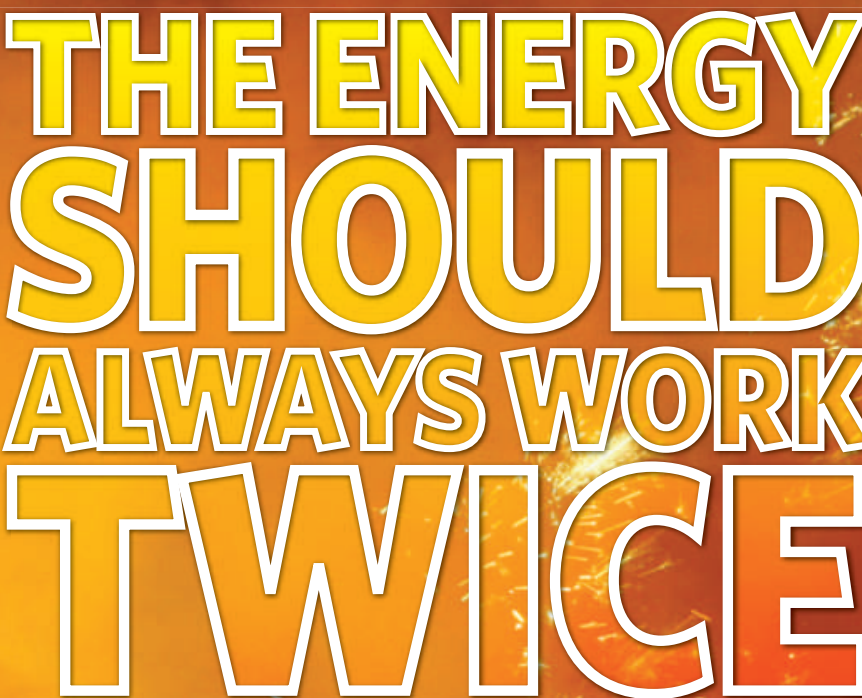

Waste heat from industrial plants and electricity-generating stations represents a huge amount of lost energy. David Lindley finds out what engineers and regulators need to do to get it back

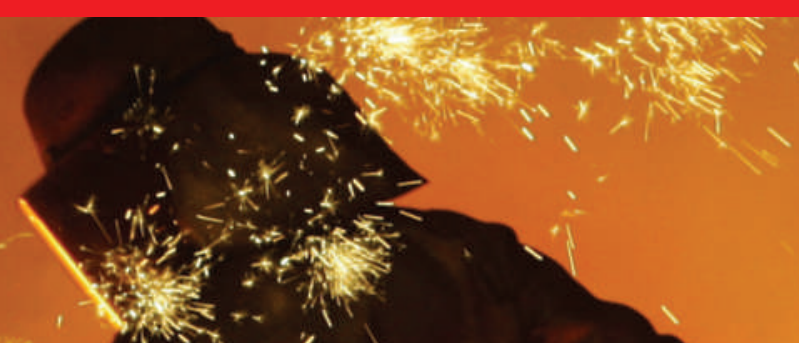

he power flows freely at West Virginia Alloys. This factory, tucked into the Kanawha River valley about 50 kilometres upstream from Charleston, West Virginia, is the second largest consumer of electricity in the state. It routinely pulls more than 120 megawatts of power from the grid, directing it into five electric arc furnaces that heat quartz to about $1,500^{\circ} \mathrm{C}$ to make highgrade silicon for computer chips, solar cells and other uses.

Then the plant takes the furnaces' $800^{\circ} \mathrm{C}$ exhaust, which still contains much of the original energy, and sends it billowing out of the smokestacks.

Unfortunately, West Virginia Alloys is not unusual, says Thomas Casten, an industrialist who has been preaching against this kind of energy waste for 30 years. Consumers around the world have embraced personal energy conservation in compact fluorescent light bulbs, home insulation and hybrid vehicles. But the industrial sector - including much of the electric power industry itself - continues to waste energy at a staggering rate. Thanks to generations of cheap energy, industrial process designers have typically had neither the expertise nor the economic incentive to do otherwise.
Now, however, West Virginia Alloys is one of a small but increasing number of companies trying to change their throwaway habits. By 2011, equipment being installed by Recycled Energy Development (RED) in Westmont, Illinois, a company that Casten co-founded in 2006, will start converting the plant's waste heat into electricity at a rate of more than 40 megawatts. That's enough to reduce the plant's power consumption by a third.

Such opportunities are everywhere, says Casten. There are 300 or so silicon plants in the world; each of them could repeat the West Virginia Alloys' story. Then there is steel. About half the steel in the United States is made by recycling scrap in arc furnaces; each furnace could recycle perhaps 15 megawatts of electricity. And for the manufacture of tyres, huge amounts of carbon black are used as a toughening agent for rubber. Carbon black is made by the partial combustion of tars, and the heat wasted could generate about 1 gigawatt of electricity.

Improving the energy efficiency of traditional fuel use is at least as good a way of protecting the environment as pushing for greater use of renewables, says Ahmed Ghoniem, a mechanical engineer at the Massachusetts Institute for Technology's Center for 21st Century Energy in Cambridge. Burning fossil fuels accounts for around $85 \%$ of the world's energy use, he says, so that a $20 \%$ increase in efficiency, "which is not unachievable", would reduce pollution and emission of greenhouse gases as much as would doubling the global proportion of 'green' energy generation - a goal that's years if not decades away, he adds. And in the United States alone, Casten says, energy recycling could offset the equivalent of about 200 gigawatts of electricity generation - about one-fifth of the nation's total capacity.

The challenge will be to get there - through a labyrinth of technological issues, costs, national energy policies and the often byzantine regulatory structures that govern electric power generation. "It's inordinately complicated to put all this together," says Casten.

\section{Technology old and new}

The good news for Casten's company and others in the energy-recycling field is that more and more potential customers are starting to pay attention. After last summer's spike in the price of oil, there is a widespread conviction that the price of energy has nowhere to go but up, however low oil prices might have fallen at the moment. 


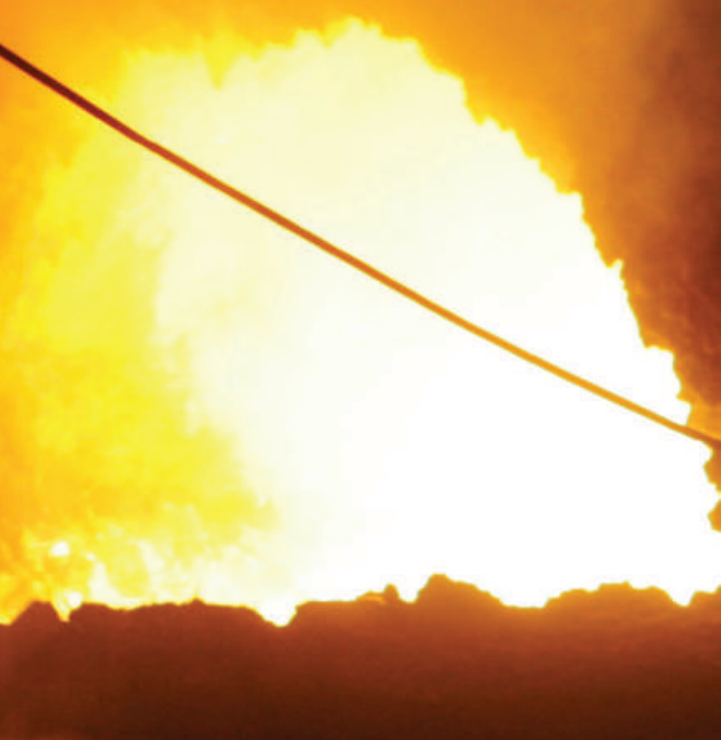

The bad news is cost: the price tag for retrofitting waste-heat recovery technology into a plant that was not designed for it tends to send potential customers into shock. The West Virginia Alloys installation will cost about US $\$ 100$ million. That is why Casten's RED, for one, supplies both the capital and the expertise for installing energy-saving systems, in return for an agreement with the company to share the benefits. Plant managers don't have the knowledge to tackle the task, says Casten. "If they look at doing this on their own they will tend to overestimate the risks and underestimate the rewards."

Still, the technology itself is straightforward; in many cases, waste heat can be turned into electricity in exactly the same way that most power plants do it. A standard plant starts by taking heat from some primary source - coal, gas, biomass, enriched uranium or even concentrated sunshine - and using it to vaporize water into high-pressure steam. The steam is then directed through a turbine: essentially an arrangement of high-tech fan blades that are forced to spin by the steam's forwards motion. The turbine's shaft rotates an electrical generator, which produces the electricity. And the steam coming out on the far side is passed through a

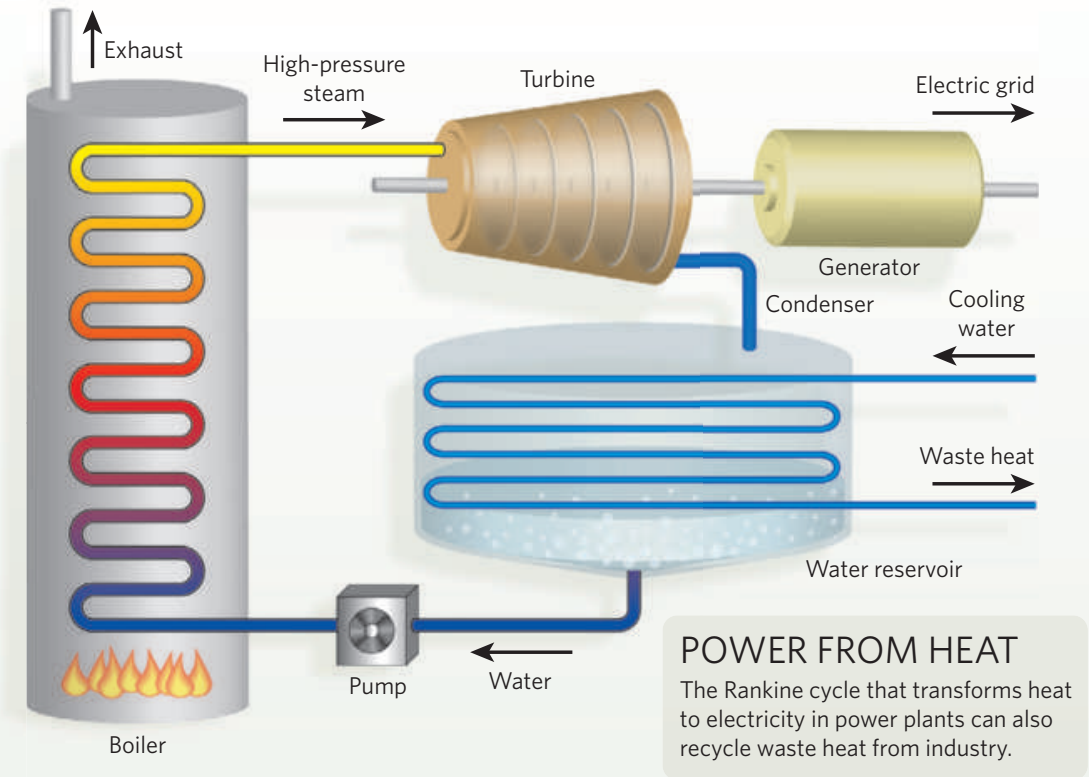

chiller that condenses it back into water again.

This Rankine cycle - named after William Rankine, the nineteenth-century Scottish engineer who devised it - is a practical and efficient way to turn a temperature difference into useful power (see 'Power from heat'). But as the French engineer Sadi Carnot showed in 1824, there is a fundamental limit on how efficient any such cycle can be. The bigger the temperature difference, the bigger that maximum efficiency is; thus engineers' frequent references to 'high-quality' heat, by which they mean that the source is much hotter than its surroundings. But no matter how good the technology, there will always be some heat energy left over. In the case of the Rankine cycle, this is primarily the energy given up by the steam as it condenses back into water. In principle, further mechanical work can be extracted from leftover heat, as long as there is at least some temperature difference with the surroundings. But usually, says Ghoniem, "because it's low quality you have to work a bit harder to get that energy out".

That's why energyrecycling companies go after high-quality heat first. At West Vir-

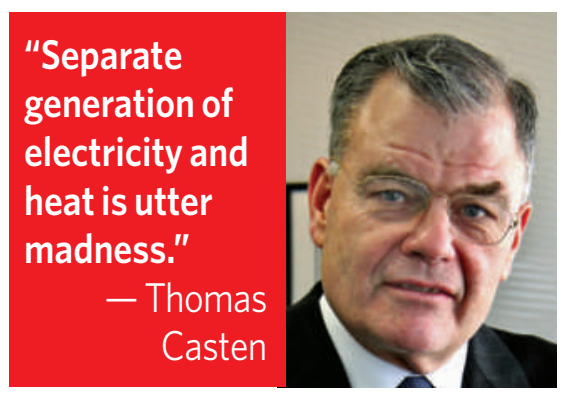

Tempting as these targets may be, there are many more opportunities to reclaim lowerquality waste heat given off in chemical manufacturing, paper making and countless other industries. RED is looking at the cavernous ovens used to dry great sheets of plasterboard (drywall) - an energy consumption that represents $80 \%$ of the plasterboard's cost. The exhaust temperature is less than $200^{\circ} \mathrm{C}$, making it hard to run a water-based Rankine cycle with any efficiency. But it is now possible to buy off-theshelf Rankine-cycle systems that replace water with more volatile liquids such as freon, propane or butane, which can extract mechanical work from more modest temperature differences.

At the high-tech frontier, meanwhile, are waste-heat recovery systems that rely on solidstate thermoelectric materials that directly generate electricity from a temperature gradient. Commercially available thermoelectric devices can attain $15-20 \%$ of the Carnot efficiency for a given temperature difference, says Jeff Snyder, a materials scientist at the California Institute of Technology in Pasadena, making them both less efficient and more expensive than a ginia Alloys, for example, the $800^{\circ} \mathrm{C}$ exhaust heat from the furnaces will be used to boil water, which will then generate electricity via a standard Rankine-cycle system. And there are planty of other examples, says Casten. He vividly remembers visiting a lime plant in Nevada that has enormous cylindrical kilns fed by limestone, pulverized coal and oxygen. "You can feel the heat 30 feet away," he says. Large-scale industries such as ore-smelting and metal-refining have conventionally pumped out energy that does nothing except heat the surrounding air.
Rankine device doing the same job. Nonetheless, their compact size and lack of moving parts make thermoelectric generators an attractive option for the automotive industry. BMW and Volkswagen, for example, have both announced prototype systems that would create electricity from the engine's exhaust heat.

Researchers are exploring more-exotic chemical compositions and materials engineered to have nanostructures to decrease thermal conductivity, slow the flow of heat and make its energy easier to capture. Any heat that 


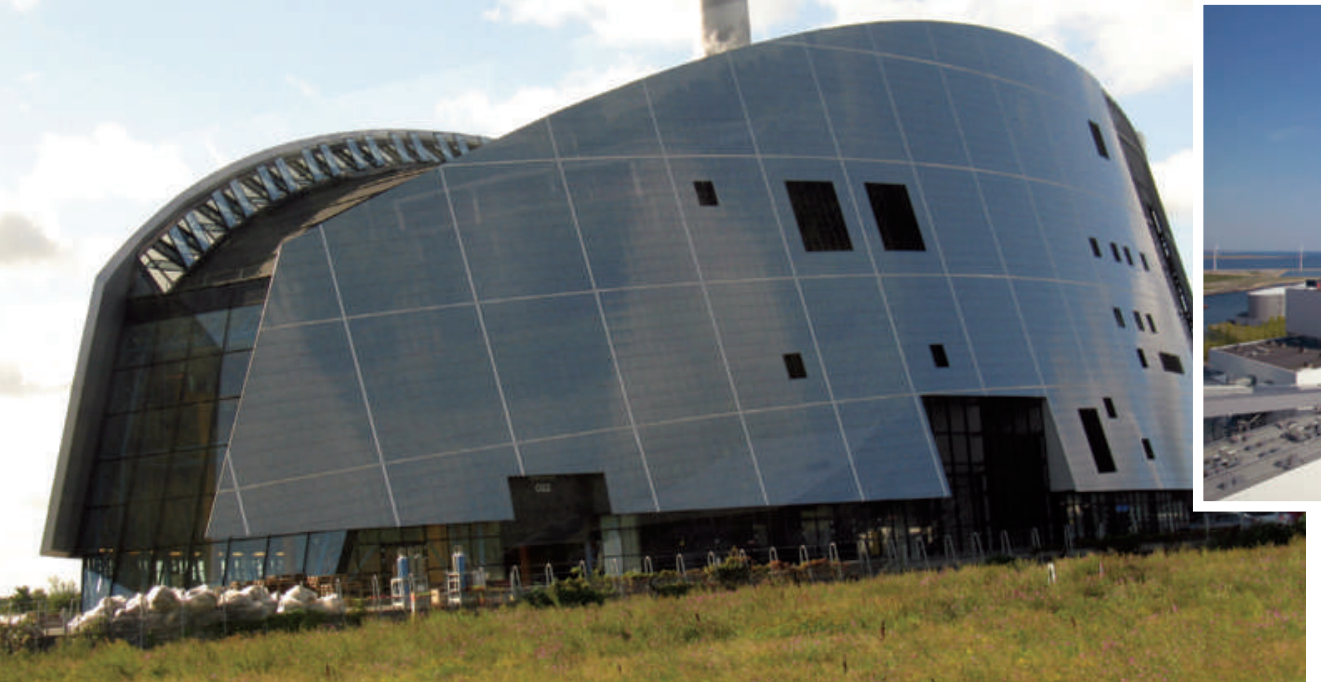

崫 flows all the way through the material is lost, says Snyder. Such systems probably won't be able to compete with Rankine-cycle technology in a factory setting, he says, but it's realistic to think of adding thermoelectric generators to vehicles at a cost a few hundred dollars.

\section{The biggest offender}

Globally, one of the most glaring inefficiencies comes from the burning of fossil fuels to generate electricity. About two-thirds of the world's electricity is made this way, according to a 2005 tabulation from the US Energy Information Agency, and the conversion efficiency in typical coal- or oil-fired plants is about one-third.

Newer electric power plants running on natural gas or on 'syngas', a mixture of mostly hydrogen and carbon monoxide created by gasification of coal, can achieve greater efficiencies through a combined cycle system, in which combustion of the gas directly drives a first set of turbines, while exhaust heat from that stage generates steam that drives a second set of turbines. Combined cycles deliver efficiencies of $55 \%$ or more, says Ghoniem.

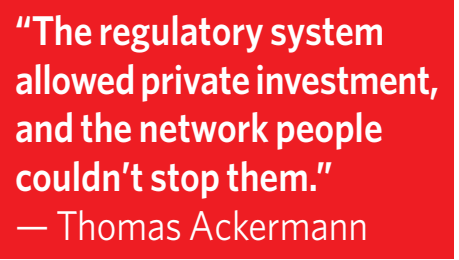
allowed private investment, and the network people couldn't stop them."

\section{Thomas Ackermann}

Gasification is a cleaner but more expensive use of coal, whereas natural gas is mostly used in 'peaker' plants that can be turned on and off quickly as changing demand requires. Combined cycle systems have therefore yet to make a significant improvement in the average efficiency of converting fossil fuels to electricity.

Still, no method for generating electricity by burning a fuel can avoid substantial inefficiency through the loss of heat - which puts utilities in the ludicrous position of venting huge amounts of waste heat to produce electricity that is often turned back into heat somewhere else, via arc furnaces, hair driers and home heating systems. So why not use that waste heat directly?
"Separate generation of electricity and heat is utter madness," says Casten, who likes to point out that the plant built by Thomas Edison in Manhattan in 1882 to supply electricity to the burgeoning city also sent its waste heat through pipes to warm nearby buildings. Such a combined heat and power (CHP) system remains in place in New York City, operated by Consolidated Edison and feeding steam heat to about 100,000 buildings.

The emphasis is on 'nearby', however; heat doesn't travel as well as electricity does. So in the United States, where the power system evolved through the twentieth century towards large power plants located in remote areas, this municipal deployment of CHP remains rare. But other countries do things differently.

Perhaps the most notable example is Denmark, which has pursued national energy policies that have put it at the forefront of energy efficiency as well as use of renewable sources, principally wind power. About half of Denmark's electricity comes from CHP plants - a few large ones, which switched from oil to coal following the oil crisis of the 1970s, and thousands of small to medium units, serving smaller communities and mostly running on natural gas. Some local units burn wood chips, straw, other biomass and household waste. "Everything that can be burned is burned," says Per Lund, head of system development at Energinet.dk, the stateowned corporation in Fredericia that runs Denmark's electricity grid.

Part of Denmark's success with CHP is a matter of geography: its large CHP plants sit close to the shore and use cold sea water for cooling. As larger temperature differences allow greater efficiency, these plants achieve efficiencies of more than $90 \%$ in terms of the electricity and useful heat obtained from their fuel. Over the

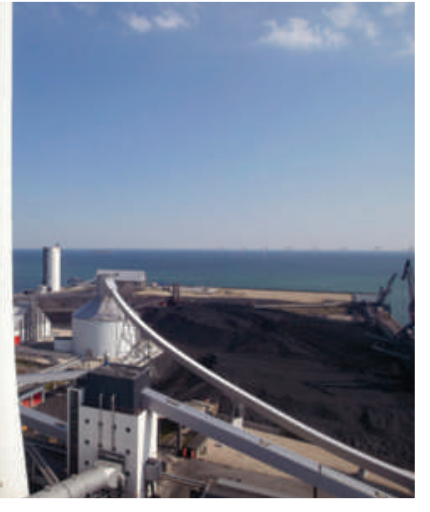

About half of Denmark's electricity comes from combined heat and power plants (such as these in Viborg, left, and Amager) that provide both electricity and heat to houses and offices.

past 25 years, Denmark's energy consumption has remained essentially constant even as the country's gross domestic product (GDP) has grown by $75 \%$, giving it the European Union's lowest 'energy intensity', measured in terms of energy consumption per unit of GDP.

But Denmark's success also derives from a mix of tight regulations, government investments and open-market responses. For example, says Lund, there was significant national spending to install the buried pipes that distribute hot water around communities of as few as 500 houses. And in CHP districts, which include about 60\% of the country's population, residents must draw their domestic heat from the centralized system. But at the same time, private investors who see a profitable opportunity in providing additional energy are free to propose building a new CHP unit. Likewise, industries that invest in equipment to capture and divert their waste heat can recoup some of their costs by selling it to the local CHP district.

\section{Keeping up with the competitors}

In the United States, Kathey Ferland, project manager at Texas Industries of the Future, an advisory organization in Austin, points out that energy-intensive oil refineries and chemical plants in Texas have long made use of CHP to achieve internal efficiencies. "What mostly seems to motivate them is making sure that they are at the least doing what their competitors are doing," she says.

However, in Texas, Ferland says, "a lot of the really good economic sites are done", and for smaller operations the economics of CHP can be hard to work out, or outright unfavourable. For example, a plant that uses CHP to meet its basic power needs may greatly reduce its consumption of off-peak electricity - a significant fraction of which comes from wind power in Texas - while still drawing on the grid when its needs are higher. CHP, therefore, competes disproportionately against the cheapest and 
most environmentally friendly electricity, without eliminating the need for conventional power plants.

So an electricity-pricing system with higher daytime prices to discourage peak consumption can create a "misincentive" by acting against other desirable goals, says Chris Marnay of the Lawrence Berkeley National Laboratory in California. "The form of the technologies that are successful is determined at least as much by the regulatory situation as it is by the engineering reality." In one study of medium-scale commercial buildings, Marnay and his colleagues found that CHP made economic sense for a hypothetical building in California, but not for the same building in New York, mainly because of differences in the electrical tariff structure.

\section{National oversight}

These regional variations arise because electricity regulation has traditionally been in the hands of the states. The 1978 Public Utility Regulatory Policies Act modified that picture, obliging US electric utility companies - at that time, a collection of local and regional monopolies - to buy electricity from independent producers. Oversight was put in the hands of individual states, which took on the task with varying degrees of enthusiasm, and the terms of the act gave utilities considerable influence over the price they were supposed to pay for independently produced electricity.

The Danish government, by contrast, mandated expansion of CHP as a national policy beginning in the 1980s, requiring grid operators to pay for the power generated at a set rate. The guaranteed ability to sell electricity stimulated the construction, by private entities, of relatively small-scale CHP plants. The same

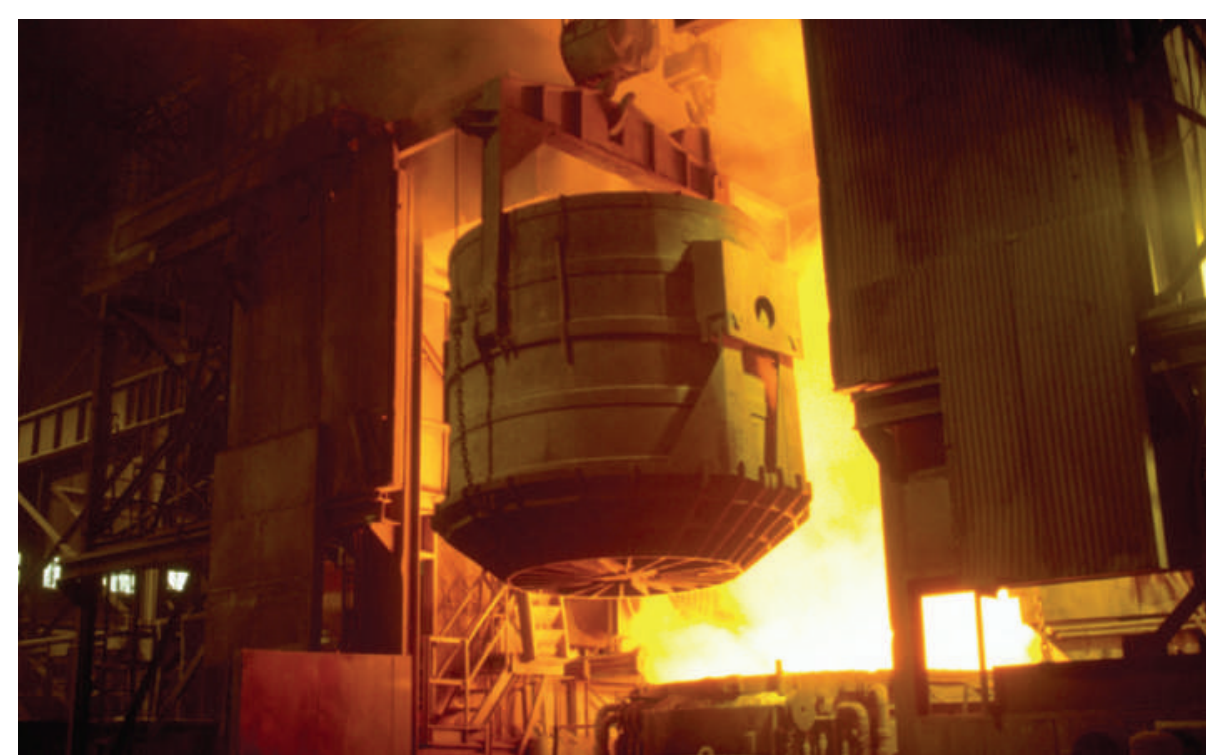

Each furnace used to turn scrap metal into steel could be used to recycle about 15 megawatts of electricity.

strategy lies behind the rapid growth of wind and solar power in Denmark and also in Germany. In both cases, grids were legally obliged to buy renewable power. Wind power, which now accounts for about $20 \%$ of Denmark's electricity supply, began as a grass-roots movement of "happy amateurs", says Lund, with farmers installing turbines made by the same companies that forged ploughs and built water tanks. Today, however, wind turbines are huge business, manufactured by a handful of large companies.

At the time, power engineers accustomed to working with grids that transmitted power over wide areas from a handful of enormous generating plants doubted that the new system could work

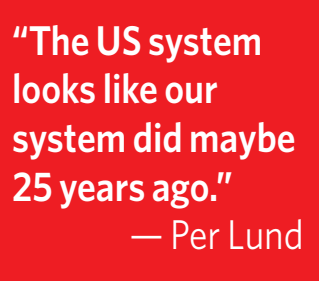

"The US system

ks ilke our reliably, says Thomas Ackermann, chief executive of Energynautics in Langen, Germany, an energy-consultancy company. A number of Danish studies argued that distributed generation - with electricity coming from many smaller-capacity suppliers - couldn't be done. And "it wasn't done, in the sense that anyone actively planned it", he says. "Instead, the regulatory system allowed private investment, and the network people couldn't stop them."

As a result, Denmark is moving towards an increasingly distributed generation system, in which electricity doesn't simply flow in a 'topdown' manner, but can also move in a 'bottomup' way from multiple small generating units. This required many changes to the way power moves through transformers from low-voltage to high-voltage parts of the network. A unified national policy of private investment aided by government subsidy spurred the construction of moderate-capacity electricity plants, and the grid operators were able to pass on costs to customers through tariffs. But in many countries, such transformations falter on the question of who will pay for them, says Ackermann.

That is typically the case in the United States, where efforts to deregulate the old monopolies have happened piecemeal. "One of the first problems is that people don't understand each other, everyone has a different mindset, everyone has a different way of looking at the system," says Ackermann. A common question is whether a distributed generating system with many small seasonally variable suppliers can ensure that peak demand will be met.

But, says Ackermann, in a reversal of the standard cliché about the free-market United States and socialist Europe, "we don't talk about guaranteeing power from wind or other sources all the time - we just believe that the market will cope". In Germany, he says, peak demand is about 74 gigawatts and the market can supply about 120 gigawatts, so that as demand waxes and wanes, more expensive producers enter and leave the market, and the price of electricity rises and falls. "The system is one of the best in the world in terms of reliability," says Ackermann. He argues that the greater regulatory burden in the United States has inhibited development of diverse generating capacity and of the grid, so that the infrastructure that gets built is the bare minimum. "The US system looks like our system did maybe 25 years ago," says Lund.

\section{Change we need?}

But change is in the air. In his Senate confirmation hearing, Steven Chu, former director of the Lawrence Berkeley National Laboratory and now US energy secretary, declared that "more efficient use of energy in the United States is the one big factor that can most help us reduce our dependency on foreign oil". The economic stimulus package signed by President Obama on 17 February includes a modest federal subsidy for CHP and recycled-energy projects. "This is the first federal inducement of generation efficiency since 1986," says Casten, although he adds that the bill promises much greater support for renewable energy sources, "which is not as good a way to spend money". He hopes that when Chu talks about efficiency, he doesn't just mean better appliances and more insulation. "The bottom line is that we will not have a prayer of mitigating climate change unless we address the efficiency of generating thermal and electric energy." David Lindley is a freelance science writer based in Alexandria, Virginia.

See Editorial, page 125. 